\title{
Managing the After Sales Logistic Network- A Simulation Study of a Spare Parts Supply Chain
}

\author{
Fredrik Persson ${ }^{1}$ and Nicola Saccani ${ }^{2}$ \\ 1 Linkoping University, Department of Management and Engineering, \\ Linköping, Sweden \\ fredrik.persson@ipe.liu.se \\ 2 Università degli Sutdi di Brescia, Department of Mechanical and \\ Industrial Engineering, Via Branze 38, 2523 Brescia, Italy \\ nicola.saccani@ing.unibs.it
}

\begin{abstract}
.
The after-sales services and in particular the spare parts business have acquired, in recent years, a strategic role for firms manufacturing durable or capital goods, as they represent a source of revenue, profit and a mean to achieve customer satisfaction and retention. Nonetheless, the huge variety and the characteristics of the demand of spare parts make the configuration and management of the spare parts inventory and distribution systems critical decision areas for managers. These decisions, in fact, may lead to very different cost and service performance by the system itself. The case study analyzed concern a world player of heavy equipment based in Sweden. Its spare parts distribution system is described, and the paper analyzes the configuration and allocation decisions concerning a second European warehouse and the transfer to that warehouse of a set of suppliers. A simulation model has been developed in order to support these choices. Discrete event simulation is well suited for studies where time-dependant relations are analyzed. Supply Chain Simulation applied to the case study provides useful insights on the decision choices and the cost structure related to the spare parts distribution system.
\end{abstract}

\section{Introduction}

Although durable goods for the consumer market as well as capital goods are designed to be reliable, i.e. to last for a long time without failures, it may happen that failures occur or that specific parts wear out with the usage. After-sales services and spare parts provision may be relevant sources of revenue, profit service 
differentiation, and customer retention (Cohen et al. [1]; Yamashina [2]; and Goffin [3]).

The management of a spare parts inventory and distribution network presents some critical aspects. First of all, a company manufacturing a durable product, notwithstanding the degree of complexity of the product (e.g. from a dishwasher to a piece of complex machinery) has to manage a huge number of spare parts. All those products, in fact, are made of quite a high number of components or subsystems that can be subject to failure and substituted. Moreover, the rate of introduction of new products has indeed increased smoothly in the last decades: the product lifetime at the customer tends to be for most durable or capital goods much longer than the lifetime of the product offer on the market. Therefore, the manufacturer should manage the spare parts of its present product catalogue as well as for the old ones, thus reaching a very high number of parts. The second aspect is inherent to the demand for spare parts. It tends to be rather low (in relation with the amount of products sold) and irregular. Demand is often related to exceptional (failure) events, which happen stochastically in time and space. Of course, the knowledge of the reliability characteristics of the product and its parts and of the installed base characteristics may help in forecasting or interpreting spare parts demand [2], but this may work correctly at an aggregate level, while it is rather difficult to predict where and when the demand will take place.

Manufacturers, in configuring and managing their spare parts inventory and distribution systems, are then faced with the typical cost vs. service trade-off. They should act, in fact, in order to satisfy their customers by ensuring spare parts availability at a short notice, while on the other hand they should minimize the costs related to inventory holding and to the risk of obsolescence. This paper tackles the above issues through the case of a manufacturer of heavy equipment located in Sweden. In particular, the aim is to evaluate different choices about the location of spare parts inventory through a simulation model. The next section provides a review of spare parts classification and the relation with inventory decisions; the third section describes the case company, the specific problem analyzed and the simulation model designed. Section four provides the main simulation findings, while some conclusions and direction for future research are drawn in the last section.

\section{Background}

\subsection{Spare parts distribution and inventory decisions}

According to Huiskonen [4], when designing and managing any logistic system, and in particular a spare parts logistic system, there are four decision levels:

- The strategy/policies/processes level concerns the objectives to be pursued by one actor or the entire supply chain (e.g. in terms of service level or response time);

- The network structure defines the number of inventory echelons and locations in the supply chain; 
- The coordination and control mechanisms include decisions about the inventory control principles, the incentive and performance measurement systems, and on the information support tools or systems to be used;

- The supply chain relationships, finally, consist of the degree of cooperation or reciprocal influence among supply chain actors that may impact on the achievement of the objectives through the implementation of the control and coordination activities.

Cohen et al. [5], focus on the interplay of spare parts allocation decisions. Decisions should be taken in order to optimize the cost-service trade-off related, as shown in figure 1 , to the product and the geographic hierarchy. For example, a company may decide to replace a failed product with a standby end product stocked at the customer's premises. This solution provides the fastest response time, but it is much more costly then deciding to replace only the broken parts with spares stocked at the company central warehouse.

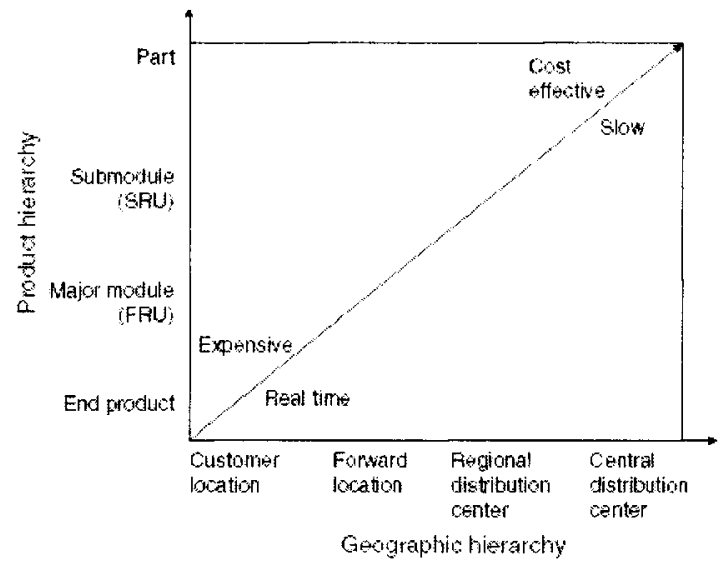

Fig. 1. The product and geography hierarchy for allocation decisions [5]

\subsection{Spare parts classification}

Some authors have treated the classification of spare parts as a way to provide guidelines on inventory management. Huiskonen [4] classifies spare parts according to four dimensions: i.) criticality, ii.) specificity, iii.) demand pattern and iv.) value. Resorting to a case example, he finds out five spare part groups, for which suggestions for inventory control policies are provided. Williams [6], and later Eaves and Kingsman [7], build their classification on the variability of spare parts demand. In particular, the lead time variance is decomposed into the contribution of: the number of orders during the lead time, the size of orders and the lead time duration. Eaves and Kingsman [7] identify 5 groups in reason of their demand pattern: smooth, irregular, slow moving, mildly intermittent, highly intermittent. Gajpal et al. [8] and Braglia et al. [9] use the AHP methodology for spare parts classification. Gajpal et al. [8] aim at assessing the spare part criticality, through a weighted measure of stock out implication, type of spare required (level of standardization) and of the lead time. Braglia et al. [9], instead, develop a multi attribute spare tree analysis. The 
classification of a spare part according to one criterion (e.g. spare part plant criticality) may lead to different decision diagrams, in which classification according to other criteria are requested. The other criteria proposed are spare supply characteristics, inventory problems and usage rate. Each classification is made through the AHP technique, and finally parts are grouped in four classes, to which inventory management guidelines are associated.

The reviewed classification methods present common elements such as the attention to criticality aspects and to the demand pattern of spare parts, although with different degrees of importance and different evaluation procedures. What emerges, also, is the fact that no classification considers directly the product and part lifecycle, that are suggested as relevant elements by Yamashima [2], and strongly influence the demand for spares.

\section{The case study}

\subsection{Simulation Methodology}

Supply Chain Simulation (SCS) is defined as the use of the simulation methodology, incorporating discrete event simulation, to analyse and solve problems found relevant to supply chain management.

Banks et al. [10] discuss what makes supply chain simulation different from other simulation applications. One major difference from e.g. simulation of manufacturing systems is that supply chain models contain information flows together with the flow of materials.

The used simulation methodology follows the steps described in Persson [11]. The first step (i) is the project planning or problem formulation where the outline of the study is determined. The next step (ii) is the conceptual modeling. The conceptual model describes the system under investigation. The conceptual model is validated as the next step (iii). The computer-based model is created as step (iv). This model must be verified (v) and validated (vi). Model verification aims at estimating if the simulation model is a valid representation of the conceptual model while model validation aims at estimating if the model is a valid representation of the system. The experimentation step (vii) consists of experimental runs with the simulation model. The results of these runs are then analyzed (viii) and the result of that analysis is the base for the recommended decision or implementation (ix). In this case study, simulation is used to calculate transportation costs in a complex setting incorporating a vast amount of data.

\subsection{The Case Company}

The case company is one of the world's leading manufacturers of heavy equipment. Production plants are located in Sweden, Western Europe, the North and South America, and in Asia. To obtain maximum profitability from the equipment and to respect scheduled activities, uptime is a critical performance for the company's 
customers. Therefore, great effort is devoted to the after-sales service, managed by a Service division headquartered Sweden. The logistics network of spare parts is depicted in figure 2 . The company's suppliers are located in all different parts of the world, shipping spare parts to the two warehouses located in Europe, of which the main warehouse (WH 1) is located in Sweden.

Spare parts inventory levels and shipments to regional warehouses and dealers are controlled by reorder point systems. If the inventory level of any spare part in the two warehouses or at the regional warehouses are below the safety stock level, an express freight is utilized. That accounts for about $10 \%$ of all freights: otherwise ordinary transports are used.

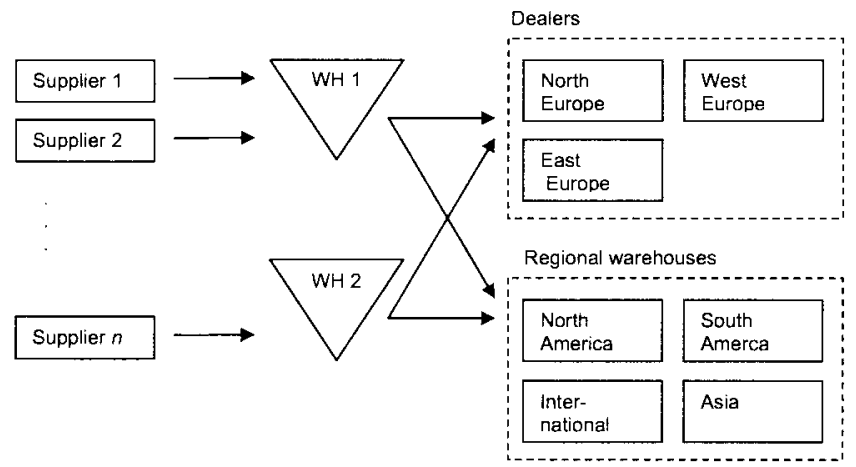

Fig. 2. Spare parts logistics network of the case company

\subsection{Problem formulation}

Today some of the suppliers of spare parts are dedicated to either the main warehouse (WH 1) located in Sweden or to warehouse WH 2. In the near future, the capacity needs to increase in WH 1 due to new forecasted higher sales volumes. One way to solve the problem would be to transfer some of the suppliers to WH 2, thereby reducing the number of suppliers storing their spare parts in Sweden and thus making storage capacity available. One restriction to the problem is that, if a supplier is moved, all spare parts supplied by that supplier must be moved.

The purpose of the case study is to investigate this transfer of suppliers from WH 1 to WH 2. This is done given the existing structure of the supply chain and taking all relevant costs into consideration. Simulation is chosen to investigate the supply chain cost structure due to two reasons: (i) The ability to handle stock outs and delays in transportations, and (ii) The reactive characteristics of the inventory control system that, among other things, determines if transportation should take place with ordinary transportation or with express.

The supply chain, as depicted in the previous section, is modeled in the simulation software Arena. The model contains 20 suppliers (out of over 800 suppliers in total). These 20 suppliers are chosen because they stand for $88,1 \%$ of the total weight, 89,7 $\%$ of total purchasing cost, and $92,5 \%$ of total number of order lines. All internal suppliers (suppliers owned by the same company) are not considered in this study. The model still covers hundreds of different parts and thousands of order lines per year. 


\section{Experiments and Results}

The simulation model in Arena was used to calculate the transportation cost for the two different cases of localisation, WH 1 or WH 2. Transportation cost is calculated as the sum of all transports, taking the cost for weight, the weight of the parts and the order class into consideration. An order class is the type of transport that the part utilises. An express transport is more expensive than an ordinary transport.

The case company presented four different scenarios of future market growth to be analysed with the simulation model. The future growth is represented by percentage increase in the demand year by year in each market. The differences between Scenarios represent solely alternative changes in the European markets; thus, two Scenarios in the same year will have the same growth in sales in Latin America, North America, Asia and the International market, but the percentage of sales in the three European markets will be different. Each scenario contains sales data for the years 2008, 2010, 2012, and 2014 for both warehouses.

The first simulation used the demand for 2006 and the results of this experiment were used as a base case to compare to the rest of the simulations. Each experiment was run twice, one run considering the cost matrix of WH 1 , the other time considering the cost matrix of WH 2.

For each future scenario the costs for each supplier was calculated in the simulation model. The difference between to place the supplier in WH 1 compared to place the supplier in WH 2 was calculated as the main result variable. If this difference is positive it means that the cost is lower when the supplier is moved from WH 1 to WH 2. The higher the positive value is in the calculations, the higher the cost savings when the supplier is moved to WH 2. In the cost calculations, the costs are split between inbound costs (transports to WH 1 and WH 2) and outbound costs (transports to regional warehouses and dealers in Europe). In some cases, both the inbound cost and the outbound cost are negative (indicating the spare part to stay at WH 1) and the conclusion to keep the part in WH 1 is unambiguous. In other cases, both costs are positive (indicating the part to be moved to WH 2) and here as well, the conclusion to move the product is clear. In the rest of the cases, the inbound and outbound costs differ and the cost levels decide the conclusion, see Table 1. This indicates that if a supplier is closer to a warehouse, it does not directly follow that the costs will decrease if it is moved to that warehouse. If the outbound costs become very high, they will surpass the benefits obtained in the inbound cost. Therefore, the location of a supplier with respect to the warehouse is not a decisive factor in finding the lowest total cost

Table 1. Cost relations

\begin{tabular}{cccc}
\hline Inbound cost & Outbound cost & Total cost & Consequence \\
\hline$<0$ & $<0$ & $<0$ & Stay in WH 1 \\
$<0$ & $>0$ & $?$ & $?$ \\
$>0$ & $<0$ & $?$ & $?$ \\
$>0$ & $>0$ & $>0$ & Move to WH 2 \\
\hline
\end{tabular}

Considering the results obtained in the first scenario, it is clear that costs can be saved if two of the suppliers (out of total 20) are moved to WH 2. Continuing with analyzing the other scenarios, the same two suppliers are suitable to be moved in every scenario. As the demand increases according to the sales forecasts there are 
two inferences: (i) for the first supplier (supplier 7) the cost savings decrease as the demand increases, and (ii) for the second supplier (supplier 13) the cost savings increase as the demand increases, see Table 2 for the costs in the base case.

Table 2. Total cost difference in base case

\begin{tabular}{lccc}
\hline WH 1-WH 2 & Inbound & Outbound $^{*}$ & Total cost \\
\hline supplier 1 & $-4 \mathrm{kr}$ & $-14 \mathrm{kr}$ & $-17 \mathrm{kr}$ \\
supplier 2 & $-4 \mathrm{kr}$ & $-4 \mathrm{kr}$ & $-8 \mathrm{kr}$ \\
supplier 3 & $-1 \mathrm{kr}$ & $-4 \mathrm{kr}$ & $-5 \mathrm{kr}$ \\
supplier 4 & $-13 \mathrm{kr}$ & $-11 \mathrm{kr}$ & $-24 \mathrm{kr}$ \\
supplier 5 & $-2 \mathrm{kr}$ & $-4 \mathrm{kr}$ & $-6 \mathrm{kr}$ \\
supplier 6 & $-3 \mathrm{kr}$ & $-2 \mathrm{kr}$ & $-4 \mathrm{kr}$ \\
supplier 7 & $4 \mathrm{kr}$ & $-3 \mathrm{kr}$ & $2 \mathrm{kr}$ \\
supplier 8 & $2 \mathrm{kr}$ & $-7 \mathrm{kr}$ & $-5 \mathrm{kr}$ \\
supplier 9 & $0 \mathrm{kr}$ & $-11 \mathrm{kr}$ & $-11 \mathrm{kr}$ \\
supplier 10 & $1 \mathrm{kr}$ & $-1 \mathrm{kr}$ & $0 \mathrm{kr}$ \\
supplier 11 & $-6 \mathrm{kr}$ & $-3 \mathrm{kr}$ & $-9 \mathrm{kr}$ \\
supplier 12 & $-43 \mathrm{kr}$ & $-48 \mathrm{kr}$ & $-90 \mathrm{kr}$ \\
supplier 13 & $110 \mathrm{kr}$ & $-10 \mathrm{kr}$ & $100 \mathrm{kr}$ \\
supplier 14 & $3 \mathrm{kr}$ & $-14 \mathrm{kr}$ & $-11 \mathrm{kr}$ \\
supplier 15 & $3 \mathrm{kr}$ & $-11 \mathrm{kr}$ & $-8 \mathrm{kr}$ \\
supplier 16 & $-18 \mathrm{kr}$ & $-1 \mathrm{kr}$ & $-19 \mathrm{kr}$ \\
supplier 17 & $-2 \mathrm{kr}$ & $-5 \mathrm{kr}$ & $-7 \mathrm{kr}$ \\
supplier 18 & $-17 \mathrm{kr}$ & $-8 \mathrm{kr}$ & $-25 \mathrm{kr}$ \\
supplier 19 & $7 \mathrm{kr}$ & $-10 \mathrm{kr}$ & $-3 \mathrm{kr}$ \\
supplier 20 & $1 \mathrm{kr}$ & $-10 \mathrm{kr}$ & $-10 \mathrm{kr}$ \\
\hline
\end{tabular}

* Numbers are indexed to hide real value

In the case of supplier 7 , outbound costs to the international warehouse from WH2 and WH1 are very similar. As well, supplier 13 is much closer to WH2 than to WH1. Thus, the benefits from reduced inbound costs are far greater than the losses from the outbound costs.

On the other hand, the inbound costs savings are decreasing compared to the outbound costs increase with increasing demand. If the demand becomes high enough, this supplier should be moved back to WH1. Therefore, the benefits of moving it to WH2 might be rejected if the case company considers the dynamics over the years.

\section{Conclusive remarks}

As illustrated in the earlier sections of this paper, the spare parts business is critical for companies both at a strategic and at an operational level. Supply chain management is then a critical lever in order to obtain the highest customer satisfaction at a reasonable cost. Three relevant aspects have been touched by this paper: the configuration of the spare parts distribution system, the allocation decisions conceming suppliers and parts, and supply chain coordination mechanisms and inventory control mechanisms. Through the case of a heavy equipment manufacturer it was clear that these issues are also interesting to a company that is trying to cut costs in the supply chain. Classification of spare parts was touched in the reduction of suppliers to include in the simulation model. Focusing on weight, order lines and capital tied up provided a list of suppliers that are important to the 
company. The case study also provided useful information about cost structures in the supply chain for spare parts. Moving a supplier from a warehouse to another is not a straight forward decision. In this case it turns out that there needs to be costs savings both inbound and outbound or that the cost saving in one of the two needs to be large to overshadow the other.

\section{Acknowledgements}

The authors would like to thanks the students Pisut Changmai, Rajesh Maddineni, Emanuele Uberti, Iuliana David for their contribution in the development of the simulation model described in the paper.

\section{References}

1. Cohen M.A., Agrawal N., Agrawal V. , (2006). Winning in the Aftermarket, Harvard Business Review, May, 84 (5), 129-138

2. Yamashima H., (1989). The service parts control problem, Engineering Costs and Production Economics, 16, 195-208

3. Goffin, K., (1999), Customer support - A cross-industry study of distribution channels and strategies, International Journal of Physical Distribution and Logistics Management 29(6), 374-397.

4. Huiskonen J., (2001). Maintenance spare parts logistics: Special characteristics and strategic choices, Int. J. Production Economics, (71), 125-133

5. Cohen M.A., Agraval N., Agraval V. , (2006). Achieving Breakthrough Service Delivery Through Dynamic Asset Deployment Strategies, Interfaces, 36 (3), 259 271

6. Williams T.M., (1984). Stock Control with Sporadic and Slow-Moving Demand, Journal of the Operational Research Society, 35 (10), 939-498

7. Eaves A., Kingsman B., (2004). Forecasting for the ordering and stock-holding of spare parts, Journal of the Operational Research Society, 55, 431-437

8. Gajpal P.P., Ganesh L.S., Rajendran C., (1994). Criticality analysis of spare parts using the analytic hierarchy process, Int. J. Production Economics, 35, 293-297

9. Braglia M., Grassi A., Montanari R., (2004). Multi-attribute classification method for spare parts inventory management, Journal of Quality in Maintenance Engineering, 10 (1), 55-65

10. Banks, J., Buckley, S., Jain, S., Lendermann, P., and Manivannan, M., (2002). "Panel session: Opportunities for simulation in supply chain management", Proceedings from the 2002 Winter Simulation Conference, pp. 1652-1658.

11. Persson, F. (2003). Discrete Event Simulation of Supply Chains, Doctoral Thesis, Department of Production Economics, Linköping Institute of Technology, Linköping, Sweden. 